\title{
What You Get is What You See: Other-Rated but not Self-Rated Leaders' Narcissistic Rivalry Affects Followers Negatively
}

\author{
Theresa Fehn ${ }^{1}$. Astrid Schütz ${ }^{2}$
}

Received: 17 April 2020 / Accepted: 17 August 2020 / Published online: 25 August 2020

(c) The Author(s) 2020

\begin{abstract}
Individuals with high levels of narcissism often ascend to leadership positions. Whereas there is evidence that narcissism is linked to unethical behavior and negative social outcomes, the effects of leader narcissism on an organization's most important resource - its employees - have not yet been studied thoroughly. Using theoretical assumptions of the Narcissistic Admiration and Rivalry Concept (NARC) and social exchange theories, we examined how leaders' narcissistic rivalry was related to follower outcomes in a sample of matched leaders and followers. Followers of leaders high in narcissistic rivalry reported less perceived supervisor support, lower quality leader-member relationships, lower performance-based self-esteem, and lower job engagement. These effects were only found when follower-rated leaders' narcissistic rivalry was used in the model but not when self-rated leaders' narcissistic rivalry was used as a predictor. This implies that the negative effects of leaders' narcissistic rivalry on followers are driven by the expression of narcissistic tendencies (i.e., destructive leader behavior). Leader development should thus focus on changing destructive leader behavior. We propose that leaders high in narcissistic rivalry can be motivated to make such changes by showing them that by hurting their followers, they will eventually undermine their own reputation and status. Furthermore, selection and promotion practices should incorporate objective measures to weaken the effects of narcissists' self-promotional tactics in these contexts and thus prevent people high in narcissistic rivalry from rising to leadership positions.
\end{abstract}

Keywords Leaders' narcissistic rivalry $\cdot$ Leadership $\cdot$ Narcissism $\cdot$ Narcissistic admiration and rivalry concept $\cdot$ Follower outcomes

Even at their best, narcissistic leaders are bound to leave damaged systems and relationships in their wake.

(Rosenthal and Pittinsky 2006, p. 619).

Leader narcissism has been discussed widely but also only selectively in the literature. Whereas it has been shown that high levels of subclinical, grandiose narcissism are related to leader emergence (Brunell et al. 2008; Grijalva et al. 2015), the question of how narcissistic leaders ${ }^{1}$ affect their surroundings has often been restricted to economical outcomes. Scholars in the field of business ethics have been

Astrid Schütz

astrid.schuetz@uni-bamberg.de

Theresa Fehn

theresa.fehn@uni-bamberg.de

1 University of Bamberg, An der Weberei 5N, 96047 Bamberg, Germany

2 University of Bamberg, Markusplatz 3, 96047 Bamberg, Germany concerned with issues that arise from narcissists' unethical and self-serving behavior on an organizational level (Blair et al. 2017; Chatterjee and Hambrick 2007). However, studies on the influence of leader narcissism on the arguably most important resource of an organization-its human capital—have yielded inconclusive or contradictory results (for an overview, see Schyns et al. 2019). Whereas some authors have argued that leader narcissism is an antecedent of abusive supervision (Padilla et al. 2007; Nevicka et al. 2018a; Waldman et al. 2018) and elicits high frustration, tension, and emotional exhaustion in followers (Hochwarter and Thompson 2012; Nevicka et al. 2018a), Wisse and Sleebos (2016) found no association between leader narcissism and abusive supervision. Furthermore, other authors have

\footnotetext{
${ }_{1}$ In the following, due to space considerations and for ease of reading, we use the term "narcissistic" for people with high levels of subclinical narcissism. Clearly, there is no dichotomy of narcissistic and not narcissistic, but the variable represents a continuum. Furthermore, we focus on grandiose, or agentic, narcissism, as opposed to vulnerable, or neurotic, narcissism, as the first form has been shown to be more relevant in the organizational context (Campbell et al. 2011).
} 
pointed out that narcissists and successful leaders have many characteristics (e.g., passion and charisma) in common (Rosenthal and Pittinsky 2006) and have raised the question of whether organizations may actually benefit from having narcissistic leaders (Campbell et al. 2011; Maccoby 2000).

Successful leadership is largely built on positive dyadic relationships (Graen and Uhl-Bien 1995), and it has been shown in other contexts that narcissists have trouble-or rather, are not interested in - building sustainable relationships (Campbell and Campbell 2009). In the business ethics literature, several studies have examined how leader narcissism relates to follower emotions, perceptions and behavior (e.g., Braun et al. 2018; Den Hartog et al. 2020; Huang et al. 2020; Liu et al. 2017; Nevicka et al. 2018b). The current study aims to further contribute to this literature by heeding claims for a more fine-grained approach in investigating narcissism (e.g., Ackermann et al. 2011; Braun 2017) through differentiating two dimensions of narcissism proposed by the Narcissistic Admiration and Rivalry Concept (NARC; Back et al. 2013). Whereas narcissistic admiration might lead to favorable social outcomes, narcissistic rivalry is presumed to go along with exhibiting devaluing behavior toward others and negative social outcomes (Back et al. 2013).

Focusing on the antagonistic dimension of narcissistic rivalry, building on theoretical assumptions regarding narcissists' behavior and relationships in the workplace, and translating empirical results from studies on narcissists' personal relationships to a work context, we propose that working for leaders high in narcissistic rivalry will negatively impact how followers feel and behave. In taking a holistic perspective, we investigated effects of leaders' narcissistic rivalry on several follower outcomes by asking: How do followers perceive leaders high in narcissistic rivalry, how is the perceived relationship with their leaders affected, how do they feel about themselves, and what is the impact on their self-reported behavior in the workplace?

By examining how leaders' narcissistic rivalry influences relevant follower outcomes in a real-life sample of matched leaders and followers, this paper contributes to the business ethics and leadership literature as follows: First, it answers the call for a more nuanced view on subclinical narcissism by distinguishing between two related but different dimensions of grandiose narcissism: narcissistic admiration and narcissistic rivalry. Distinguishing between these dimensions can help answer the question of whether there is a "healthy dose" of narcissism (Craig and Amernic 2011) and shed light on earlier inconclusive results. We drew on the Narcissistic Rivalry and Admiration Concept (Back et al. 2013) and social exchange theories (Cropanzano and Mitchell 2005; Graen and Uhl-Bien 1995) as theoretical foundations for examining the effects of these two dimensions of narcissism on follower outcomes. Second, as Braun (2017) outlined in a thorough literature review, previous studies in this context used leaders' self-reports of their narcissism levels as well as other-ratings. This is in line with, for instance, Carlson et al. (2011), who argued that whereas narcissists do have selfinsight, disentangling whether self- and other-perceptions differ is worthwhile, as leaders and their followers should each have "unique insight" (Vazire and Mehl 2008, p. 1202) into leaders' typical behavior. Indeed, other-ratings of personality can be more predictive of behavior than self-ratings (Connelly and Ones 2010), especially regarding narcissism (Braun 2017; Hogan and Fico 2011). Whereas previous research has shown that self- and other-ratings of narcissism can have differential effects on interpersonal outcomes, such studies have mostly used unidimensional measures such as the Narcissistic Personality Inventory (NPI; Raskin and Hall 1979; for an overview, see Braun 2017). Research that has used multidimensional conceptualizations of narcissism (e.g., the NARC) while simultaneously incorporating both self- and other-perspectives on a person's narcissism is still scarce. We aim to further contribute to the literature in the field by integrating and comparing leaders' and followers' perspectives on leaders' narcissistic rivalry as the maladaptive dimension of narcissism to prevent same-source biases and the issues that arise when measuring "dark" personality traits with only self-reports (Spain et al. 2013).

\section{Literature Review and Derivation of Hypotheses}

\section{Conceptualizing Narcissism}

As a subclinical personality trait, narcissism is characterized by a pervasive pattern of grandiosity and self-importance, a constant need for attention and admiration, and feelings of entitlement (Back and Morf 2018; Schütz et al. 2004). Contemporary models have taken a closer look at the conceptualization of narcissism, as research on the factor structure of various narcissism scales has distinguished several facets, and empirical findings have repeatedly shown that narcissism is related to positive (e.g., charmingness, extraversion, initial popularity, dating success) as well as negative behavioral tendencies and outcomes (e.g., exploitative and manipulative behavior, arrogance, social disapproval, conflicts; for an overview, see Back and Morf 2018). In an attempt to explain these seemingly paradoxical correlates and outcomes, several multidimensional models of narcissism (see Back and Morf 2018; Krizan and Herlache 2018; Miller et al. 2016) have distinguished between agentic, antagonistic, and neurotic aspects. In these models, grandiose narcissism contains antagonistic (e.g., low agreeableness, arrogance, exploitativeness, entitlement) and agentic aspects (e.g., extraversion, grandiosity, dominance, leadership).

In line with these considerations, the Narcissistic Admiration and Rivalry Concept (NARC; Back et al. 2013) suggests 
two distinct but related dimensions of grandiose narcissism. The agentic dimension, called narcissistic admiration, is characterized by self-promotional attempts to enhance narcissists' grandiose self-views by striving for uniqueness, entertaining fantasies of one's own grandiosity, and seeking social admiration through charming behavior and self-presentational tactics. This typically leads to positive social outcomes (e.g., popularity, attraction, and social status). Through feedback processes, the perception of these outcomes provides an ego-boost and further reinforces selfenhancement. The antagonistic dimension, called narcissistic rivalry, is based on efforts to protect one's grandiose self-views by devaluing and derogating others to feel superior. These efforts result in aggressive behavior and social conflict, which in turn threatens the narcissist's ego and thus leads to increased self-defensive strategies. As we aimed to examine potentially negative effects of leader narcissism in the workplace, we focused on the maladaptive dimension of grandiose narcissism: narcissistic rivalry.

\section{Narcissism and Leadership}

Because narcissists are likely to seek out contexts that provide the opportunity to enhance or maintain their grandiose self-views, they tend to strive for leadership positions more often than people low in narcissism (Abeyta et al. 2017; Chen 2016; Nevicka et al. 2011a). Indeed, not only do narcissists seek out contexts that confirm their grandiose selfviews, but they are also perceived as being more suitable for leadership positions, even in zero-acquaintance contexts (Brunell et al. 2008; Ong et al. 2016) and irrespective of their actual performance (Nevicka et al. 2011b). This finding can be explained by implicit leadership theories: People have general beliefs about what a "typical" leader should be like (Epitropaki et al. 2013). In many respects, narcissists match these preconceptions by generally showing dominant, extraverted, self-assured, and confident behavior - the "ingredients we tend to look for in a leader" (De Hoogh et al. 2015, p. 474). Indeed, a meta-analysis by Grijalva et al. (2015) showed that narcissists' propensity to ascend to leadership positions could be explained by high levels of extraversion. After attaining leadership positions, however, narcissists are not necessarily effective leaders. Only when leaders rate themselves is narcissism positively related to leader effectiveness. When rated by their followers, supervisors, or peers, leader narcissism is unrelated or negatively related to leader effectiveness (Grijalva et al. 2015).

Undoubtedly, "good" or "effective" leadership to a large part entails successfully leading - as opposed to merely managing-others (Kotter 1990). Positive reciprocal relationships between leaders and followers are crucial for ensuring individual motivation, performance, and well-being and thus achieving organizational goals (Dulebohn et al.
2012; Martin et al. 2010). Furthermore, holding a leadership position entails a moral responsibility to not abuse the power this role affords. Narcissists, however, are focused on their own needs and have been shown to manipulate and use others as long as it serves their own goals (Blair et al. 2017; Campbell et al. 2011). Whereas some authors have not found negative effects of leader narcissism on follower well-being (Volmer et al. 2016), others have reported negative effects of leader narcissism on follower job engagement, emotional well-being, and tension, especially in the absence of effective coping strategies in followers (Ellen et al. 2017; Hochwarter and Thompson 2012; Nevicka et al. 2018a). Concerning the impact of leader narcissism on follower behavior, Braun et al. (2018) showed that leader narcissism elicits malicious envy in followers, leading to supervisordirected counterproductive work behavior. A closer look at narcissistic leaders' behavior revealed that they tend to engage in less relational-, task-, and change-oriented behavior than others do: They show little concern for their followers, do not develop efficient communication patterns, do not define or organize their work and roles, and do not encourage innovative thinking (Martin et al. 2016). Furthermore, several recent studies found a connection between leader narcissism and abusive supervision tendencies (i.e., leaders' propensity to show hostile verbal and nonverbal behavior toward their followers, e.g., by humiliating or ignoring them; Nevicka et al. 2018a; Waldman et al. 2018; but see Wisse and Sleebos 2016, for different results).

In sum, findings concerning the effects of leader narcissism on follower outcomes are often equivocal, and a clear picture has yet to emerge. Whereas some authors have focused on the "bright side" of being led by narcissists (e.g., Higgs 2009; Maccoby 2000), other business ethics scholars have investigated the negative consequences of the "dark side" of narcissism (Blair et al. 2008, 2017; Ellen et al. 2017; Hochwarter and Thompson 2012). A very likely reason for the earlier inconclusive findings is that these previous studies conceptualized narcissism as a unidimensional construct, ignoring the potential differences between the agentic and antagonistic dimensions of grandiose narcissism.

To apply a more fine-grained perspective, here, we relied on the NARC (Back et al. 2013) as a theoretical framework that could be applied to overcome this limitation and paint a clearer picture of differential outcomes. As mentioned above, building substantive individual relationships with followers can be seen as one of the elementary aspects of being a successful leader. However, leaders with high levels of narcissistic rivalry might not be successful at building relationships or might not be motivated to do so (Bradlee and Emmons 1992). To develop specific hypotheses, studies on interpersonal relationships in a private context that have already used the NARC will be presented in the following paragraphs. Whereas private relationships arguably differ 
from leader-follower relationships, it has been shown that core aspects such as respect, trust, and obligation are central to the functioning of both types of relationships, and a perceived lack of these factors leads to issues such as lower relationship satisfaction (Clark and Mills 2011; Dulebohn et al. 2012; Graen and Uhl-Bien 1995).

\section{Narcissistic Rivalry in Relationships}

Relationships evolve and change over time. Several studies have shown that narcissists create positive initial impressions in relationships as they are perceived as charming, attractive, assertive, and exciting in the so-called "emerging zone" (e.g., Back et al. 2018; Paulhus 2001). Yet, in the long term, the positive impression wanes, and narcissists are increasingly perceived as manipulative, cold, arrogant, untrustworthy, or combative. Consequently, relationship satisfaction declines (Campbell and Campbell 2009; Lavner et al. 2016; Leckelt et al. 2015; Paulhus 1998; Wurst et al. 2017). This process can be traced back to the dimensions of narcissism proposed in the NARC: Narcissistic admiration is responsible for the initial positive effects of narcissism in interpersonal relationships, explained by dominant, expressive behavior and being perceived as assertive. By contrast, the negative long-term effects hail from narcissistic rivalry, manifested in exploitative, arrogant behavior and being perceived as aggressive (Back et al. 2018; Küfner et al. 2013; Wurst et al. 2017). Whereas the positive effects of narcissistic admiration decrease with time, the negative effects of narcissistic rivalry increase (Leckelt et al. 2015).

Thus, while narcissistic admiration may even lead to positive consequences in workplace relationships, narcissistic rivalry should have a negative impact on interaction partners, especially if the interactions last for a long period of time. As we did not study newly formed relationships in the workplace, we expected negative effects of narcissistic rivalry in established relationships. Relations between leaders' narcissistic admiration and follower outcomes were additionally investigated in an exploratory manner.

\section{Leaders' Narcissistic Rivalry and Follower Outcomes}

To capture a broad range of follower experiences, we investigated perceptions as well as reported behavior in followers. Importantly, we included followers' and leaders' ratings of leaders' narcissistic rivalry to examine whether the results varied by source (see Back et al. 2013). Even though self- and other-ratings of narcissistic rivalry are moderately related ( $r=0.27$; Back et al. 2013), narcissists can be expected to perceive themselves differently (i.e., in a more positive light) than their interaction partners do, and using self- and other-ratings captures both perspectives. Whereas narcissism is traditionally measured via self-report, several authors have suggested using other-ratings of personality traits especially when researching so-called "dark" personality traits or at least supplementing self-ratings with otherratings (Spain et al. 2013; Thomas et al. 2003). Specifically, Malesza and Kaczmarek (2018) posited that other-ratings may supplement self-ratings of narcissism as other-ratings contain a degree of unique, trait-relevant information. In this study, we investigated how individual follower outcomes (e.g., self-esteem and engagement) are affected by followers' and leaders' perceptions of leaders' narcissistic rivalry to prevent same-source biases.

\section{Perceived Supervisor Support}

According to social exchange theories, relationships in the workplace consist of reciprocal interactions (Cropanzano and Mitchell 2005; Graen and Uhl-Bien 1995; Thoroughgood et al. 2018): If supervisors provide task-related information and resources and show empathic concern and support, followers reciprocate with motivation, commitment, and loyalty. A meta-analysis (Ng and Sorensen 2008) showed that perceived supervisor support was positively related to relevant follower outcomes (e.g., job satisfaction, affective commitment, and turnover intentions). These, in turn, ultimately influence an organization's success (Ostroff 1992). Other researchers found that perceptions of supervisor support influenced not only job-related attitudes but also behavioral tendencies, such as actual turnover (Eisenberger et al. 2002) or organizational citizenship behavior (Chang et al. 2018). Individuals high in narcissistic rivalry are focused on their own advantage but lack empathy and concern for their interaction partners (Back et al. 2013). They show arrogant and aggressive behavior and are perceived as untrustworthy (Leckelt et al. 2015). Moreover, people high in narcissistic rivalry describe themselves as less committed and less faithful in relationships compared with individuals who score lower (Wurst et al. 2017). Thus, leaders high in narcissistic rivalry may be perceived as showing little interest in supporting their followers.

Hypothesis 1a: Self-rated leaders' narcissistic rivalry will be negatively related to perceived supervisor support.

Hypothesis $1 \mathrm{~b}$ : Follower-rated leaders' narcissistic rivalry will be negatively related to perceived supervisor support.

\section{Relationship Quality}

The need to belong and establish meaningful personal relationships is innate in humans, and the failure to satisfy that need has meaningful negative consequences for physiological and psychological well-being (Baumeister and Leary 1995; Holt-Lunstad et al. 2010; Mellor et al. 2008). In the 
workplace, positive relationships between leaders and followers are characterized by mutual respect, trust, and loyalty according to the leader-member-exchange framework (Graen and Uhl-Bien 1995). The quality of leader-follower relationships has substantial effects on relevant organizational and individual outcomes, such as turnover intentions and actual turnover, in-role and extra-role performance, commitment, job satisfaction, and well-being (Dulebohn et al. 2012; Martin et al. 2010). A meta-analysis found that leader personality was the best predictor of the quality of these relationships (Dulebohn et al. 2012). Narcissistic rivalry is associated with uncaring, devaluing, and manipulative behavior as well as low levels of empathy and agreeableness (Back et al. 2013). In romantic relationships, it has been shown that narcissists exhibit manipulative, uncaring behavior and make their partners feel unsupported, which in turn leads to decreased relationship quality (Lavner et al. 2016). We expect that these expressions of narcissistic rivalry are reflected in followers' negative evaluations of the leader-member relationship. As the quality of relationships greatly relies on the extent to which we feel supported by our interaction partners (Clark and Mills 2011; Sue-Chan et al. 2012), we expect perceived supervisor support to mediate this relationship.

Hypothesis 2a: Self-rated leaders' narcissistic rivalry will be negatively related to followers' perceived quality of leadermember relationships. This relation will be mediated by perceived supervisor support.

Hypothesis 2b: Follower-rated leaders' narcissistic rivalry will be negatively related to followers' perceived quality of leader-member relationships. This relation will be mediated by perceived supervisor support.

\section{Performance-Based Self-Esteem}

In the workplace, people are often confronted with challenging situations. How well we think we can handle these situations influences our performance (Judge et al. 2007; Stajkovic and Luthans 1998). One benefit of positive interactions with others is that they can enhance the trust we have in our ability to cope with challenging situations (Bandura 1986). We base part of our self-esteem on the presumed evaluations of others (Leary and Baumeister 2000). In line with the assumption that self-esteem fluctuates with others' approval or rejection, a meta-analysis showed that social relationships had a significant effect on self-esteem (Harris and Orth 2019).

If positive interactions with others can make people feel worthy and capable of handling challenging tasks, interactions with leaders high in narcissistic rivalry, who devaluate and derogate their followers and put themselves above them, should erode followers' trust in their abilities at work (i.e., decrease their performance-based self-esteem). In line with Sguera et al. (2018), we argue that perceived supervisor support plays an important role in this relationship, as low levels of perceived support should lead followers to conclude they are not worthy. Thus, we expect the assumed negative relationship between leaders' narcissistic rivalry and performance-based self-esteem to be mediated by perceived supervisor support.

Hypothesis 3a: Self-rated leaders' narcissistic rivalry will be negatively related to performance-based self-esteem. This relation will be mediated by perceived supervisor support.

Hypothesis 3b: Follower-rated leaders' narcissistic rivalry will be negatively related to performance-based self-esteem. This relation will be mediated by perceived supervisor support.

\section{Job Engagement}

An organization's success depends to a large degree on the effort each follower invests in fulfilling the tasks that come with his or her respective role (Katz and Kahn 1978). Job engagement (i.e., the full investment of one's physical, cognitive, and emotional resources) in a specific role is positively related to task and extra-role performance (Kahn 1990; Rich et al. 2010). According to social exchange theory, relationships in the workplace are reciprocal (Cropanzano and Mitchell 2005): Organizations provide job security, financial compensation, and attractive tasks through their leaders; followers reciprocate by fulfilling their tasks and investing effort to try to reach organizational goals. In sustainable relationships, leaders show that they appreciate and value their followers, thus motivating their followers to go above and beyond set goals (Dulebohn et al. 2012; Graen and Scandura 1987). Hence, we expect that when leaders devalue their followers and place themselves above them, followers will reciprocate with reduced job engagement. As derogating behavior should be perceived as unsupportive, we expect perceived supervisor support to mediate this relationship (Fig. 1).

Hypothesis 4a: Self-rated leaders' narcissistic rivalry will be negatively related to job engagement. This relation will be mediated by perceived supervisor support.

Hypothesis 4b: Follower-rated leaders' narcissistic rivalry will be negatively related to job engagement. This relation will be mediated by perceived supervisor support.

We conducted an exploratory investigation to determine how leaders' narcissistic admiration relates to the abovementioned outcomes. 
Fig. 1 Proposed theoretical model

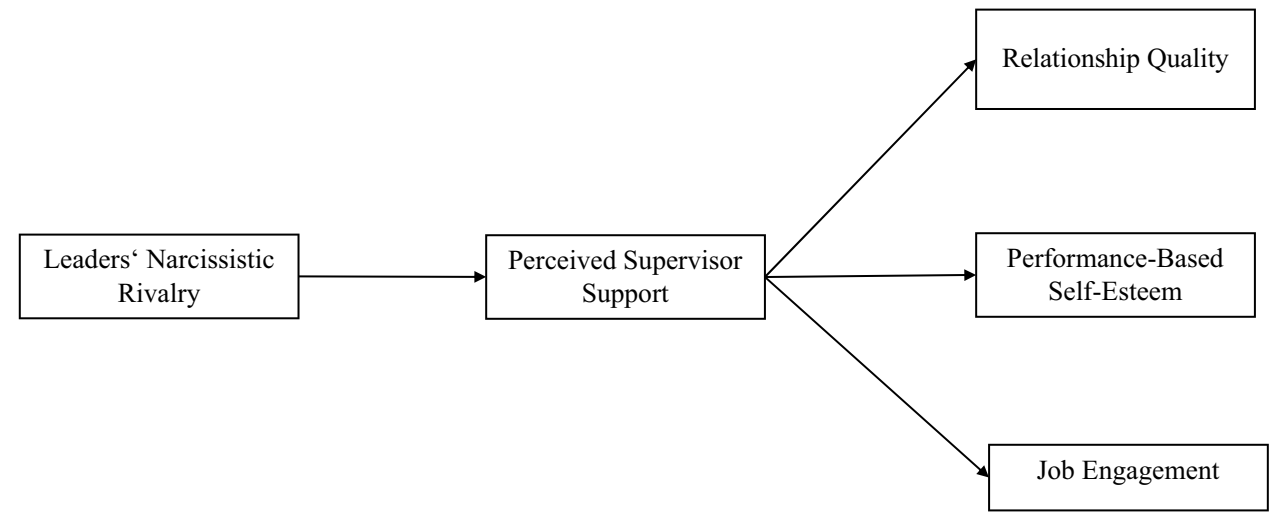

\section{Method}

\section{Sample and Procedure}

As mentioned above, we included leaders' and followers' perspectives in our research. Leaders were approached via the quarterly newsletter of the authors' competence center, the authors' university press department, personal contacts, and online platforms (e.g., www.xing.de). As we wanted to increase the probability that at least one follower per leader would participate, thus gaining as many usable matches as possible, leaders were asked to submit the e-mail addresses of three followers who were then invited to participate in the study. To ensure an unbiased choice of followers and to prevent leaders from picking only followers who could be expected to provide favorable assessments, we asked leaders to name the three followers whose last names came first in the alphabet as long as they had been working together for at least 6 months.

Heeding calls for more transparency in psychological research, the theoretical model and main hypotheses were preregistered on the Open Science Framework (OSF; see https://osf.io/q4ahw/). ${ }^{2}$

Participants took part in the study on a voluntary basis. Anonymity and confidential treatment of data were stressed to avoid concerns about the respective leaders or followers obtaining access to the data. The initial sample consisted of 142 leaders and 168 followers. Six participants were excluded due to a large number of missing items or symmetrical answer patterns. Several participants could not be matched to either a leader or a follower. After leaders and followers had been matched, the final sample consisted of 122 followers nested under 68 leaders. There were on average 1.8 followers per leader (range $1-5$ ).

\footnotetext{
${ }^{2}$ We preregistered further variables and hypotheses that will be reported in a separate manuscript.
}

In the final sample, $41 \%$ of leaders and $70 \%$ of followers were women. Leaders were between 25 and 61 years old $(M=45.71, S D=10.62)$, and followers were between 20 and $65(M=38.62, S D=12.35)$. Respondents came from over ten industries, with the most prevalent being civil services (32.8\%). Leaders directly supervised between one and 60 followers $(M=9.81, S D=9.86)$. Out of the leaders, $14.7 \%$ held a high (i.e., top management), $32.4 \%$ a medium (i.e., department level), and $52.9 \%$ a low (i.e., team level) leadership position. Followers had worked for their current supervisors for 4.68 years on average (range $0-29 ; S D=5.54$ ).

\section{Measures}

\section{Narcissistic Rivalry and Admiration}

To assess narcissistic rivalry and admiration, we used the 18-item German version of the Narcissistic Admiration and Rivalry Questionnaire (NARQ; Back et al. 2013). Leaders rated themselves and were evaluated by their followers with an other-rating version of the questionnaire. Sample items are "I want my rivals to fail/My supervisor wants his/ her rivals to fail" (rivalry) or "I show others how special I am/My supervisor shows others how special he/she is" (admiration). The items were answered on a 6-point Likert scale ranging from 1 (not at all) to 6 (completely). Internal consistency was acceptable to good for the self-ratings with Cronbach's $\alpha=0.69$ for rivalry and Cronbach's $\alpha=0.76$ for admiration and excellent for the follower ratings with Cronbach's $\alpha=0.94$ for rivalry and Cronbach's $\alpha=0.87$ for admiration.

\section{Perceived Supervisor Support}

We assessed perceived supervisor support with the adapted Perceived Organizational Support Scale (Eisenberger et al. 1997, 2002), which consists of nine items (e.g., "My supervisor really cares about my well-being"). Items were rated on a 6-point Likert scale ranging from 1 (do not agree at all) 
to 6 (strongly agree). The scale was translated into German using the standard forward- and back-translation procedure (Brislin 1986). The items were translated into German by the first author and then translated back into English by a bilingual research assistant. Discrepancies between the original and the back-translated versions were resolved before the German version was finalized. Cronbach's alpha was excellent $(\alpha=0.90)$.

\section{Leader-Member-Exchange}

We used the German version of the Multidimensional Leader-Member-Exchange Scale (LMX-MDM; Paul and Schyns 2004) to measure leader-member-exchange quality. Responding to the authors' recommendations, only three of the four subscales were used (affect, loyalty, and respect), each containing three items (e.g., "I like my leader very much as a person"). Answers were indicated on a 7-point Likert scale ranging from 1 (do not agree at all) to 7 (strongly agree). The internal consistency was excellent $(\alpha=0.93)$.

\section{Performance-Based Self-Esteem}

We measured performance-based self-esteem with the five items comprising the subscale performance self-esteem of the State Self-Esteem Scale (Heatherton and Polivy 1991; German version by Rudolph et al. 2020). A sample item is "I feel frustrated or rattled about my performance". Participants rated the items on a 5-point Likert scale with answers ranging from 1 (not at all) to 5 (completely). The internal consistency was acceptable $(\alpha=0.68)$.

\section{Job Engagement}

Job engagement in this study was operationalized as the extent to which followers invest effort in their work tasks and measured with the subscales physical and affective engagement from the Job Engagement Scale (Rich et al. 2010), each consisting of six items. Again, we used the standard forward- and back-translation procedure to translate the items into German. Sample items are "I feel energetic at my job" (emotional engagement) or "I exert my full effort to my job" (physical engagement). The items were rated on a 5-point Likert scale ranging from 1 (do not agree at all) to 5 (strongly agree). The internal consistency was excellent $(\alpha=0.91)$.

\section{Control Variable}

As negative affectivity may influence followers' perceptions and evaluations of their leaders, we controlled for negative follower affect. We used the German version of the Positive and Negative Affect Schedule (PANAS; Krohne et al. 1996), which consists of 10 adjectives (e.g., "nervous", "upset"). Followers indicated the extent to which they were presently experiencing the respective affective states on a 5-point Likert scale $(1=$ not at all to $5=$ extremely; Cronbach's $\alpha=0.87)$.

\section{Analysis Strategy}

The data were hierarchically structured, as between one and five followers evaluated variables concerning their respective leader's personality and their mutual relationships. Consequently, evaluations of followers (level 1) nested in leaders (level 2) were nonindependent, and this nested structure had to be taken into account to prevent the underestimation of standard errors (Hox 2010; Nezlek 2011). As effects on different levels were not relevant to the research question, but the dependence of the data due to the clustered structure had to be accounted for, we opted for the Mplus type $=$ complex analysis strategy (Muthén and Muthén 1998-2012). This procedure adjusts the standard errors for nonindependence of observations but does not yield effects on different levels or cross-level interactions.

The intraclass correlation (ICC), which measures the degree of dependence within a group (Snijders and Bosker 2012), was 0.09 for performance-based self-esteem, 0.12 for job engagement, and 0.53 for leader-member-exchange. However, according to Kahn (2011), using multilevel modeling even with low ICCs is sensible, as ICCs as low as 0.10 can imply meaningful heterogeneity between groups.

We estimated two different models. In Model 1, the leaders themselves rated their narcissistic rivalry levels (IV), and followers rated perceived supervisor support (mediator) as well as leader-member-exchange, performance-based selfesteem, and job engagement (DVs), resulting in a 2-1-1 model with multivariate outcomes. In a second model, all variables were measured from the followers' perspective, resulting in a 1-1-1 model. We specified maximum likelihood estimation with robust standard errors, which is robust to violations of normality and appropriate when cluster sizes are unbalanced (Heck 2015).

\section{Results}

Data management and preliminary analyses were carried out using IBM SPSS Statistics for Windows, version 25 (IBM Corp. 2017). Descriptive statistics, intercorrelations, and internal consistencies are presented in Table 1.

\section{Hypothesis Testing}

Analyses concerning hypothesis testing were carried out using Mplus, version 7.2 (Muthén and Muthén 1998-2012). 
Table 1 Means, standard deviations, correlations, and internal consistency estimates

\begin{tabular}{|c|c|c|c|c|c|c|c|c|c|c|c|}
\hline Variable & $M$ & SD & 1 & 2 & 3 & 4 & 5 & 6 & 7 & 8 & 9 \\
\hline \multicolumn{12}{|l|}{ Leader variables } \\
\hline 1 Rivalry self-rating & 1.88 & 0.52 & $(0.69)$ & & & & & & & & \\
\hline 2 Admiration self-rating & 3.13 & 0.65 & $0.42 * * *$ & $(0.76)$ & & & & & & & \\
\hline \multicolumn{12}{|l|}{ Follower variables } \\
\hline 3 Rivalry follower rating & 2.01 & 1.10 & & & $(0.94)$ & & & & & & \\
\hline 4 Admiration follower rating & 3.35 & 1.07 & & & $0.61 * * *$ & $(0.87)$ & & & & & \\
\hline 5 Perceived supervisor support & 4.96 & 0.87 & & & $-0.64 * * *$ & $-0.31 * *$ & $(0.90)$ & & & & \\
\hline 6 Performance-based self-esteem & 4.23 & 0.59 & & & $-0.33 * * *$ & $-0.21 *$ & $0.36^{* *}$ & $(0.68)$ & & & \\
\hline 7 Job engagement & 4.08 & 0.60 & & & -0.08 & -0.03 & $0.24 * *$ & $0.28 * *$ & $(0.91)$ & & \\
\hline 8 Leader-member-exchange & 5.52 & 1.20 & & & $-0.53 * * *$ & -0.14 & $0.75 * *$ & 0.16 & $0.19^{*}$ & $(0.93)$ & \\
\hline 9 Followers' negative affect & 1.30 & 0.43 & & & $0.29 * *$ & $0.28 * *$ & $-0.29 * *$ & $-0.24 * *$ & -0.11 & $-0.23^{*}$ & $(0.87)$ \\
\hline
\end{tabular}

$N_{\text {leaders }}=68, N_{\text {followers }}=122$. Alpha coefficients are given in parentheses along the diagonal

${ }^{*} p<0.05$. $* * p<0.01 . * * * p<0.001$

To test the direct and indirect effects proposed in the theoretical model, two multilevel path models controlling for the clustered data structure were analyzed, using self- and follower-rated leaders' narcissistic rivalry and admiration as predictors, respectively. As mentioned above, leaders' narcissistic rivalry was our focal predictor, whereas effects of leaders' narcissistic admiration were analyzed in an exploratory fashion only. Self- and follower-rated leaders' narcissistic rivalry were not correlated $(r=-0.06, p=0.505)$, and there were no significant mean differences between the selfand follower ratings $(t=1.31, p=0.192)$. In both models, we controlled for followers' negative affect.

The fit for Model 1, with self-rated leaders' narcissistic rivalry and admiration as predictors, was good $($ RMSEA $=0.00, \mathrm{CFI}=1.00, \mathrm{TLI}=1.14, \mathrm{SRMR}=0.01)$. Model 2, with followers' ratings of leaders' narcissistic rivalry and admiration, had a worse fit $(\mathrm{RMSEA}=0.19$, $\mathrm{CFI}=0.95, \mathrm{TLI}=0.56, \mathrm{SRMR}=0.09$ ). Excluding the control variable greatly improved the fit for Model 2 $(\mathrm{RMSEA}=0.00, \mathrm{CFI}=1.00, \mathrm{TLI}=1.00, \mathrm{SRMR}=0.00$ ). As the parameter estimates did not differ greatly when Model 2 included versus did not include the control variable, we report the results for the model with the better fit (i.e., in which negative follower affect was not controlled for). ${ }^{3}$ Parameter estimates for Model 1 and 2 are reported in Table 2.

Hypothesis 1a, which posited a negative relationship between self-rated leaders' narcissistic rivalry and perceived supervisor support, was not supported $(\beta=-0.11$, $S E=0.15, p=0.445)$. In line with Hypothesis $1 \mathrm{~b}$, we found a

\footnotetext{
${ }^{3}$ Parameter estimates for Model 2 including followers' negative affect as a control variable are reported in Table 3 for the sake of completeness.
}

negative relationship between follower-rated leaders' narcissistic rivalry and perceived supervisor support $(\beta=-0.72$, $S E=0.07, p<0.001)$.

In Hypotheses $2 \mathrm{a}$ and $2 \mathrm{~b}$, a negative relationship between self- and follower-rated leaders' narcissistic rivalry and leader-member-exchange was expected to be mediated by perceived supervisor support. Self-rated leaders' narcissistic rivalry did not predict leader-member-exchange $(\beta=0.01$, $S E=0.07, p=0.903$ ), which went against H2a. Followerrated leaders' narcissistic rivalry, in turn, predicted follower ratings of leader-member-exchange, but the effect was beyond traditional levels of significance $(\beta=-0.23$, $S E=0.13, p=0.072$ ). Furthermore, the effect was mediated by perceived supervisor support as expected $(b=-0.52$, $S E=0.11, p<0.001)$.

The negative relation between leaders' narcissistic rivalry and performance-based self-esteem postulated in Hypotheses $3 \mathrm{a}$ and $3 \mathrm{~b}$ was not evident for self-rated leaders' narcissistic rivalry $(\beta=0.12, S E=0.09, p=0.179)$ or followerrated leaders' narcissistic rivalry $(\beta=-0.14, S E=0.14$, $p=0.332$ ). However, as expected, there was a significant indirect effect from follower-rated leaders' narcissistic rivalry to performance-based self-esteem via perceived supervisor support $(b=-0.10, S E=0.04, p=0.028$ ).

Hypotheses $4 \mathrm{a}$ and $4 \mathrm{~b}$ proposed a negative relation between leaders' narcissistic rivalry and job engagement, mediated by perceived supervisor support. Again, no significant direct effect was found for self-rated $(\beta=0.07$, $S E=0.09, p=0.472)$ or follower-rated leaders' narcissistic rivalry ( $\beta=0.13, S E=0.12, p=0.293$ ). However, the indirect effect from follower-rated leaders' narcissistic rivalry to job engagement via perceived supervisor support was significant $(b=-0.13, S E=0.04, p=0.001)$. 


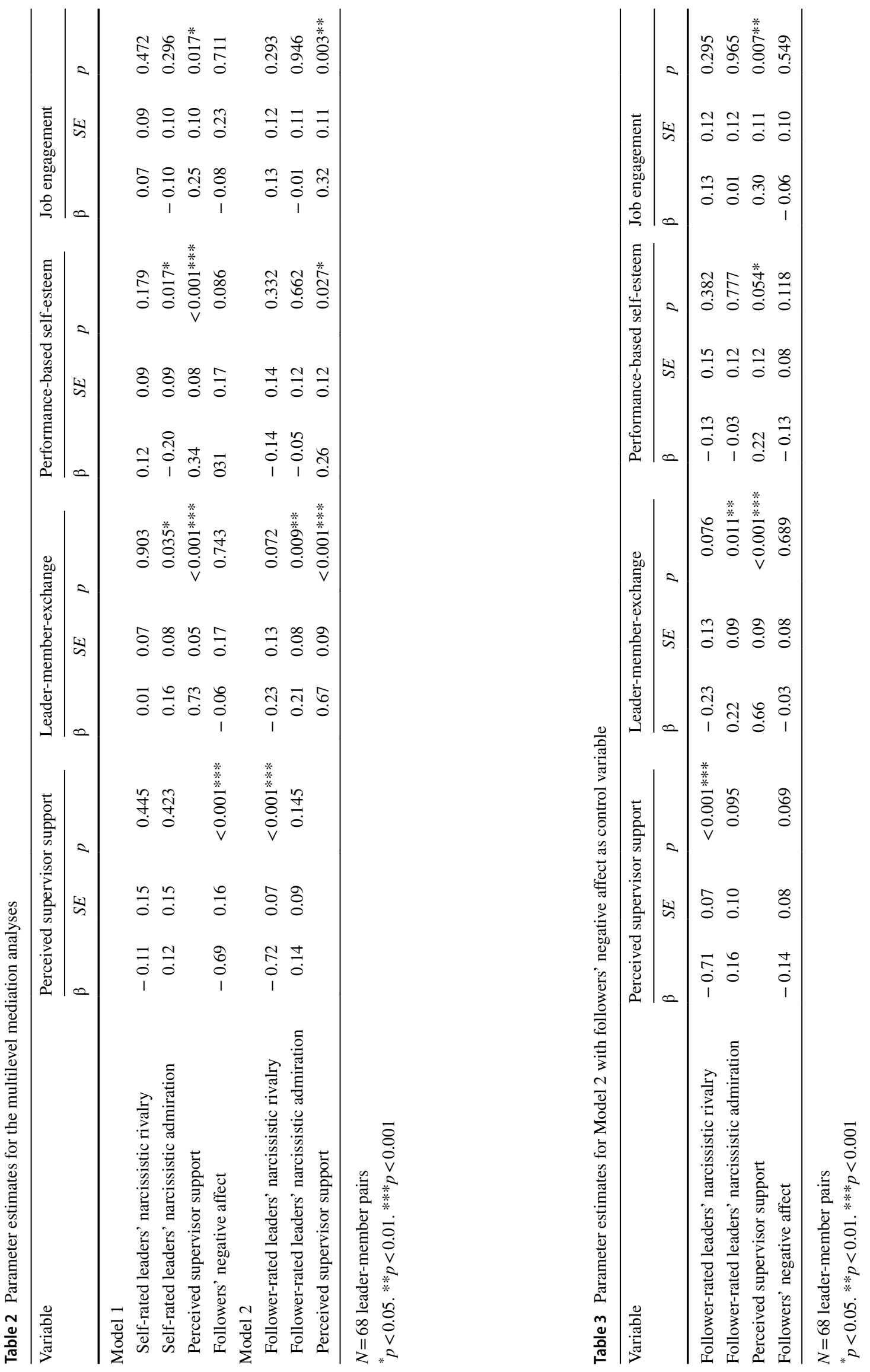




\section{Additional Analyses}

For many decades, the Narcissistic Personality Inventory (NPI; Raskin and Hall 1979; German version by Schütz et al. 2004) has been the predominant measure in research on grandiose narcissism. Only in recent years have instruments that conceptualize narcissism as a multidimensional construct emerged. To examine whether results differ on the basis of the conceptualization of narcissism as one- or two-dimensional, we also tested the theoretical model with self-rated leader narcissism as measured by the NPI as a predictor. Again, we included followers' negative affect as a control variable. The model fit the data very well $(\mathrm{RMSEA}=0.00, \mathrm{CFI}=0.1 .00, \mathrm{TLI}=1.00, \mathrm{SRMR}=0.00)$. Scores on the NPI did not predict perceived supervisor support ( $\beta=-0.09, S E=0.13, p=0.474)$, leader-memberexchange $(\beta=0.08, S E=0.07, p=0.277)$, performancebased self-esteem $(\beta=-0.15, S E=0.08, p=0.060)$, or job engagement $(\beta=-0.12, S E=0.08, p=0.149)$. Indirect effects were not significant (all $p s>0.474$ ).

The relationships between narcissistic admiration and follower outcomes were investigated in an exploratory fashion. Follower-rated narcissistic admiration was positively related to leader-member-exchange ( $\beta=0.21, S E=0.08, p=0.009$ ). Self-rated leaders' narcissistic admiration was negatively related to performance-based self-esteem $(\beta=-0.20$, $S E=0.09, p=0.017)$ and positively related to leader-member-exchange ( $\beta=0.16, S E=0.08, p=0.035)$. There were no significant indirect effects via perceived supervisor support (all $p \mathrm{~s}>0.160$ for follower-rated leaders' narcissistic admiration and all $p \mathrm{~s}>0.383$ for self-rated leaders' narcissistic admiration).

\section{Discussion}

\section{Key Findings and Theoretical Implications}

Narcissists are characterized by particular motivations and behaviors that facilitate their ascent to leadership positions (Abeyta et al. 2017; Chen 2016; Nevicka et al. 2011a). However, once there, only they themselves would describe them as "good" leaders. The current study focused on the maladaptive dimension of leader narcissism (i.e., narcissistic rivalry) in a business ethics context and integrated leaders' and followers' perspectives to try to explain why it is that others do not evaluate narcissistic leaders positively. We suggested that, similar to romantic or private relationships, the followers of leaders high in narcissistic rivalry perceive these leaders as unsupportive and that this results in negative outcomes concerning followers' perceptions, feelings, and reported behavior. In sum, the results showed a consistent picture: Self-rated leaders' narcissistic rivalry was unrelated to followers' perceptions of supervisor support and emotional and motivational outcome variables. Followers' ratings of leaders' narcissistic rivalry, by contrast, were negatively connected to these outcomes. Perceived supervisor support mediated the negative effects of follower-rated leaders' narcissistic rivalry on leader-member-exchange, performance-based self-esteem, and job engagement.

We investigated the proposed relationships in a sample of matched leaders and followers. Our results clearly show that when it comes to the motivational, emotional, and behavioral consequences of leaders' narcissistic rivalry, what counts is followers' perceptions of leaders rather than leaders' self-perceptions. Thus, if leaders high in narcissistic rivalry admit that they have devaluing thoughts and see others as less worthy than themselves but these cognitions are not manifested in behavior, followers seem to be largely unaffected. Only if the derogatory attitudes toward others are transformed into actual, perceptible behavior that is observed by followers do negative effects occur. Leaders high in narcissistic rivalry seem to behave in such a way toward their followers that these in turn feel less supported, feel less valuable, evaluate their relationships more negatively, and show less engagement.

To further examine whether it is indeed the acting out of derogatory thoughts and attitudes about others that drives the negative effects of leaders' narcissistic rivalry, future studies could examine abusive supervision as a behavioral expression of these cognitions. Even though narcissism has already been proposed as an antecedent of abusive supervision (Nevicka et al. 2018a; Padilla et al. 2007; Waldman et al. 2018), at least one study found no significant relationship between narcissism and abusive supervision (Wisse and Sleebos 2016). Thus, investigating the mediating role of abusive supervision in the relationship between narcissistic rivalry as the maladaptive dimension of narcissism and perceived supervisor support could shed further light on the actual behavior of leaders high in narcissistic rivalry. To get closer to capturing actual behavior, diary studies using event-sampling techniques could be a valuable approach here.

Previous research has yielded contradictory statements regarding the viability of using self- or other-ratings of narcissism to predict individual outcomes. Hoffmann et al. (2013), for example, found that self-rated leader narcissism did not predict follower-rated leader effectiveness. The authors referred to previous studies reporting weak relationships between self-ratings of leader narcissism and other-ratings of leadership variables and argued that treating narcissism as a unidimensional construct might have caused the positive and negative effects to cancel each other out. By distinguishing between narcissistic admiration and rivalry in our study, we circumvented that pitfall and showed that the two dimensions of narcissism proposed in the NARC are 
related to follower outcomes in different ways. Indeed, our additional analyses using the unidimensional NPI did not reveal significant effects of leader narcissism on our outcome variables and thus clearly differed from the results using follower ratings of narcissistic rivalry as the maladaptive dimension of narcissism.

This finding supports the assumption that positive and negative effects of grandiose narcissism might cancel each other out when unidimensional measures are used and further strengthens the argument for using more fine-grained approaches to measurement. However, it is still possible that a negativity bias influenced our results: Followers might have attributed general negative attitudes or affectivity to their leaders, biasing their evaluations of the leaders and their relationships. We lowered this possibility by controlling for followers' negative affectivity. Additionally, the results dovetail with previous research that showed that other-ratings of personality were more predictive of behavior than self-ratings (Connelly and Ones 2010), especially concerning evaluations of narcissism (Braun 2017). As Hogan and Fico (2011) contended, narcissistic leaders' reputation (i.e., how they are perceived by others) is especially useful for predicting leader behavior. To further corroborate this claim, we recommend combining followers' perspectives on leaders' narcissistic rivalry with objective measurements of actual leader behavior in future studies to thus better understand the links between narcissistic rivalry, abusive supervision, and perceived supervisor support.

The findings from our study are partly in line with findings on private or romantic relationships, which show that long-term partners of narcissists do not feel cared for, report manipulative behavior and conflicts, suffer from a lack of commitment and warmth, and are generally not satisfied with their relationships (Campbell and Foster 2002; Campbell et al. 2006; Lavner et al. 2016; Wurst et al. 2017). We also corroborate the findings by Wurst et al. (2017), who did not operationalize narcissism as a unidimensional construct but distinguished between narcissistic admiration and rivalry. Like them, we showed that particularly the rivalry dimension of narcissism entails negative outcomes for interaction partners, and we can add that this holds true not only in private but also in work contexts.

Of course, all relationships develop and change over time. In connection with the NARC, it has been shown that the rivalry component is responsible for the negative longterm effects of narcissism in relationships, such as rejection, conflicts, or unpopularity (Leckelt et al. 2015; Wurst et al. 2017). In turn, narcissistic admiration generates the positive social outcomes typical of narcissists, such as being perceived as attractive and likable or attaining social status and praise (Back et al. 2018; Leckelt et al. 2015; Wurst et al. 2017). Consequently, it is possible that leader-member relationships are likewise affected by these temporal trajectories.
If this is the case, the stronger influence of narcissistic admiration in early relationships may lead followers to perceive their narcissistic leaders as more supportive, and negative outcomes should be less obvious. In the long run, however, as the rivalry dimension becomes more influential, negative social outcomes, such as low perceived support, low follower engagement, reduced self-esteem, and unsatisfactory relationships should predominate. This argument is also in line with results from Nevicka et al. (2018b), who found that less visible leaders, who had less opportunity to treat their employees negatively in comparison with more visible leaders, had a less negative impact on followers' job attitudes.

To examine temporal effects, we analyzed our theoretical model using the duration of the leader-member relationship as a moderator in a post hoc analysis. Surprisingly, it was not the case that followers who had only worked with their supervisors for a short time evaluated their relationship more favorably. This finding differs from the results of studies in romantic or private contexts, which showed that the relationship satisfaction of people with narcissistic partners declines over time (Lavner et al. 2016) and that this can be attributed to the differential predominance of the admiration and rivalry dimensions over the course of a relationship (Leckelt et al. 2015; Wurst et al. 2017). Still, we excluded pairs who had worked together for less than 6 months, and it is possible that the negative effect of leaders' narcissistic rivalry has already been substantiated after a few months (see Paulhus 1998). Thus, future research could examine the assumptions we made in newly formed leader-member collaborations. Longitudinal studies would definitely be worthwhile to shed further light on the temporal effects of narcissism and draw causal conclusions regarding the development of work relationships with narcissistic leaders. For instance, it may also be the case that work relationships differ from private relationships in certain aspects (e.g., the emotional significance one attributes to them).

Our exploratory investigation of narcissistic admiration in the context of leader-member relationships showed that leaders who perceive themselves or are perceived as high on narcissistic admiration have better leader-follower relationships than others. In this respect, it may be worthwhile to investigate the overlap between narcissistic admiration and components of transformational leadership to learn more about the processes underlying this effect. Transformational leaders inspire their followers by communicating compelling visions in a charismatic way (Bass 1991). Judge et al. (2006) did not find associations between leader narcissism and transformational leadership. This could be due to their use of a unidimensional narcissism measure. Applying the NARC in this context may show whether narcissistic admiration is indeed positively related to transformational leadership. According to the NARC, people high in narcissistic admiration entertain visions of grandiosity (Back et al. 
2013), which might, in an organizational context, apply to visions for one's organization. It may thus be the case that leaders high in narcissistic admiration form relationships with their followers that are perceived as positive because these leaders share motivating visions and give followers the feeling that they are part of something big and important.

However, self-rated leaders' narcissistic admiration was negatively related to followers' reports of performance-based self-esteem. This shows that leaders who aim to be the center of attention and praise their own accomplishments seem to elicit feelings of inadequacy in their followers regarding work performance. In this sense, leaders' narcissistic admiration may also be regarded as maladaptive in some respects: Based on social comparison processes, negative feelings toward the leader may be elicited because the leader triggers feelings of inferiority. Followers who experience low performance-based self-esteem typically show less satisfaction and lower performance (Judge and Bono 2001). Further, malicious envy and supervisor-directed counterproductive work behavior could result (Braun et al. 2018; Whelpley and McDaniel 2016).

\section{Limitations}

Whereas the dyadic data structure of our sample enabled us to study our theoretical assumptions from two perspectives, some methodological aspects could be improved in future studies. First, we had an unbalanced sample: We asked leaders to invite up to three of their followers. We did so to increase the possibility that at least one follower per leader would answer the questionnaire. Future studies could use balanced and unique dyads and collect ratings on all variables of interest from both partners so that actorpartner-interdependence models (APIM; Kenny and Cook 1999) could be computed.

Furthermore, we asked leaders to select the followers according to their surnames, but we were unable to control whether they actually did so. Biases could have influenced our sample in such a way that leaders intentionally invited followers from whom they expected favorable ratings. However, followers' ratings of most variables were comparable to those reported in the literature in the field, which speaks against possible biases. Leaders' self-rated narcissistic rivalry was indeed lower than in previous papers: Whereas others found ratings between 1.92 and 2.70 (e.g., Lange et al. 2016; Leckelt et al. 2015; Geukes et al. 2017; Mota et al. 2019), the mean was 1.86 in our study. This could have resulted from our acquisition strategy: To cover the whole range of narcissism and attract leaders high in narcissism, we claimed we were looking for leaders who would share with us what characterizes "outstanding" leaders. This might have provoked socially desirable answers concerning narcissistic rivalry. However, other studies have shown that typically, social desirability is not a problem with narcissism. Additionally, other studies have reported higher variance in selfreported narcissistic rivalry than our study. Many other studies have used student samples (for an exception, see Lange et al. 2016), with a younger population and a larger share of female participants. Whereas the use of real-life leadermember pairs instead of a student sample is a strength of our study that impacts external validity, in the future, sampling strategies should ensure that there is enough variance in all relevant variables. This could be achieved by asking leaders to provide at least three followers' names and have an algorithm choose one randomly.

Of course, leadership does not happen in a vacuum. According to trait activation theory (Tett and Burnett 2003), the manifestation of personality traits depends on the situation, which in turn is shaped by contextual factors and interaction partners' behavior. In line with this, the framework of the toxic triangle (Padilla et al. 2007; Thoroughgood et al. 2018) presumes that destructive leadership emerges as a consequence of destructive leaders, susceptible followers, and conducive environments. One environmental factor that may buffer against the negative effects of narcissistic leaders on their followers is coworker support. According to the job demands-resources model (Bakker and Demerouti 2007) and the cross-domain buffering hypothesis (Lepore 1992), coworker support can be seen as a job resource that is beneficial to followers' well-being and engagement. For example, strong support from team members weakens the negative relationship between abusive supervision and job satisfaction (Hobman et al. 2009). Future studies should also take into account follower characteristics and organizational culture. On the basis of theoretical accounts and empirical findings on destructive leadership (Padilla et al. 2007; Schyns et al. 2019), we would expect that especially followers who are perceived either as "easy targets" (i.e., submissive followers) or as highly threatening to a leader's grandiose ego (i.e., confrontational followers) will suffer from having a leader high in narcissistic rivalry. For example, Nevicka et al. (2018a) found that followers with low self-esteem suffered more from narcissistic leaders than those with higher self-esteem. Also, whether an organization's culture prohibits or sanctions unethical and devaluing behavior should influence how openly narcissistic leaders display their derogative attitudes. Leaders' narcissistic rivalry might also elicit unethical follower behavior in two ways: for one, supervisor-directed deviance or counterproductive work behavior might result as ways of retaliation or protest against devaluing leader behavior (Braun 2017). On the other hand, obedient followers could be easily convinced to engage in other-targeted unethical behavior that contributes to leaders' self-serving goals (Uhl-Bien and Carsten 2007). Finally, a leader is of course not characterized by a single personality trait. In fact, it has been shown that some 
leader characteristics can temper the negative effects of leader narcissism. Basing their research on paradox theory (Smith and Lewis 2011), Owens et al. (2015), for example, showed that leader humility buffered the negative effects of leader narcissism. Future studies could thus further examine other moderating leader characteristics.

\section{Practical Implications}

The central implication of our results seems evident: We do not recommend that organizations hire people high in narcissistic rivalry for leadership positions. Of course, it is not as easy as that. Besides narcissists' propensity to seek out and achieve leadership positions (Grijalva et al. 2015), executive assessment, especially in Germany, is slow to embrace personality tests as valid selection tools (Schuler et al. 2007). Whereas such tests are fairly well-established in the US, and their use has increased in Germany as well (Hossiep et al. 2015), human resource specialists often refrain from using personality assessments due to concerns about validity and acceptance, especially in hierarchically high positions (Benit and Soellner 2013). Apart from the possibility of using general psychometric measures such as the NARQ (Back et al. 2013) in personnel selection, a first measure for specifically assessing "dark" personality traits in the work context was recently introduced (Schwarzinger and Schuler 2016). Due to the abovementioned reasons, the extent to which this will be used in the field remains to be seen. Indeed, as narcissists do have self-insight and openly admit to their narcissism (Carlson 2013), such measures might not even be needed, as one could just ask candidates whether they would describe themselves as narcissistic. In addition to personality tests, conditional reasoning tests or objective performance measures should be incorporated into selection and promotion procedures to circumvent self-presentational tactics that influence more subjective methods such as job interviews or assessment centers (Braun 2017; LeBreton et al. 2007). However, as we noted at the beginning of this paper, leadership success depends on interpersonal skills to a large extent. Thus, specifically selecting for desirable personality traits such as integrity, empathy, or agreeableness, which typically do not coincide with narcissistic rivalry (Back et al. 2013; Rogoza et al. 2016; Wetzel et al. 2016), could also help organizations avoid having people high in narcissistic rivalry ascend to leadership positions. Even before selection processes begin, organizations could influence whether people high in narcissistic rivalry even apply for a position by framing job descriptions with a focus on agentic versus communal aspects. As the latter opposes the way narcissists construe their self-views (Back et al. 2013; Grijalva and Zhang 2016), they should be less motivated to apply for such positions.
Once narcissists have obtained leadership positions and are negatively affecting their followers, other measures should be taken to minimize negative outcomes. Being a relatively stable personality trait that decreases slightly over the life span and in reaction to life events (Chopik and Grimm 2019; Grosz et al. 2019; Wetzel et al. 2019), narcissism in itself is hardly affected by training programs or coaching. This can be attributed to narcissists being resistant to critical feedback about themselves (Bushman and Baumeister 1998; Kernis and Sun 1994).

However, there might be some leverage regarding narcissistic behavior: Our findings show that leaders' narcissistic rivalry's negative effects on employees can be traced back to followers' perceptions of their leaders' behavior (i.e., the observable expressions of narcissistic rivalry). Thus, one strategy could be to work with leaders who are high in narcissistic rivalry on the behavioral expression of their attitudes toward others. As narcissists seldom see reasons to change unless circumstances challenge or threaten their grandiose self-views (Brunell and Campbell 2011), it may be important to alert them to the negative impact their behavior has on their reputation (e.g., through decreasing follower well-being and performance). Seeing that by hurting others, they eventually hurt their own standing in an organization could make behavioral change self-relevant for leaders high in narcissistic rivalry, as such positive changes could boost their status and thus foster their grandiose self-views (Grapsas et al. 2019). Training or coaching that builds on multisource feedback and thus raises narcissistic leaders' awareness of the contrast between how they see themselves and how colleagues, followers, supervisors, and clients perceive them and that focuses on practicing positive leadership skills could also be helpful here. Additionally, designing performance ratings to take into consideration supportive leadership behavior might be a further incentive for leaders high in narcissistic rivalry to adapt the behavioral expression of their narcissistic tendencies. Furthermore, whereas narcissism itself is relatively stable, certain aspects that come with it can indeed be improved through training (e.g., their lack of empathy, perspective taking, or emotional intelligence; Geßler et al. 2020; Hepper et al. 2014; Köppe et al. 2019). These aspects positively influence leader-member relationships (Cropanzano et al. 2017). In addition, organizations could enable employees to engage in upward ethical leadership by helping them develop strong networks and upward leadership skills as well as establishing strong organizational norms that promote ethical behavior and speaking up about destructive leadership behavior (Uhl-Bien and Carsten 2007; Thoroughgood et al. 2018). Finally, closely monitoring potentially destructive leaders and establishing disciplinary procedures for destructive leader behavior, taking feedback from followers seriously, and ensuring 
employee rights can further help organizations avoid the negative effects of leaders' narcissistic rivalry.

\section{Conclusion}

Leaders high in narcissistic rivalry are perceived as less supportive by their followers, which, according to followers' reports, results in lower performance-based self-esteem, lower job engagement, and worse evaluations of the leadermember relationship. What drives these effects is probably not leaders' self-evaluation but rather how their narcissistic tendencies translate into actual behavior, which is then perceived by their followers. Studies with behavioral data could help to corroborate this assumption.

Whereas leaders' narcissistic rivalry clearly has negative consequences, narcissistic admiration may have beneficial effects on how leaders are perceived. Links to charisma, vision, and facets of transformational leadership need to be further investigated. As narcissists typically look for a stage to shine from and thus seek and often attain leadership positions, organizations should consider using personality tests as well as objective selection methods in executive assessments and implement training and coaching opportunities that focus on raising leaders' self-awareness for their destructive behaviors and replacing them with constructive leadership behaviors. Establishing the motivation to change in leaders high in narcissistic rivalry, for example, by outlining how devaluative or aggressive behavior can impair a leader's reputation, is key in such endeavors.

Acknowledgements We thank Jane Zagorski for language editing.

Funding Open Access funding provided by Projekt DEAL.

\section{Compliance with Ethical Standards}

Conflict of interest The authors declare that they have no conflict of interest.

Open Access This article is licensed under a Creative Commons Attribution 4.0 International License, which permits use, sharing, adaptation, distribution and reproduction in any medium or format, as long as you give appropriate credit to the original author(s) and the source, provide a link to the Creative Commons licence, and indicate if changes were made. The images or other third party material in this article are included in the article's Creative Commons licence, unless indicated otherwise in a credit line to the material. If material is not included in the article's Creative Commons licence and your intended use is not permitted by statutory regulation or exceeds the permitted use, you will need to obtain permission directly from the copyright holder. To view a copy of this licence, visit http://creativecommons.org/licenses/by/4.0/.

\section{References}

Abeyta, A. A., Routledge, C., \& Sedikides, C. (2017). Material meaning: Narcissists gain existential benefits from extrinsic goals. Social Psychological \& Personality Science, 8, 219-228. https ://doi.org/10.1177/1948550616667618.

Ackerman, R. A., Witt, E. A., Donnellan, M. B., Trzesniewski, K. H., Robins, R. W., \& Kashy, D. A. (2011). What does the Narcissistic Personality Inventory really measure? Assessment, 18(1), 67-87. https://doi.org/10.1177/1073191110382845.

Back, M. D., Küfner, A. C. P., Dufner, M., Gerlach, T. M., Rauthmann, J. F., \& Denissen, J. J. A. (2013). Narcissistic admiration and rivalry: Disentangling the bright and dark sides of narcissism. Journal of Personality and Social Psychology, 105(6), 10131037. https://doi.org/10.1037/a0034431.

Back, M. D., Küfner, A. C. P., \& Leckelt, M. (2018). Early impressions of grandiose narcissists: A dual-pathway perspective. In A. D. Hermann, A. B. Brunell, \& J. D. Foster (Eds.), Handbook of trait narcissism: Key advances, research methods, and controversies (pp. 309-316). Cham: Springer.

Back, M. D., \& Morf, C. C. (2018). Narcissism. In V. Zeigler-Hill \& T. K. Shackelford (Eds.), Encyclopedia of personality and individual differences. Cham: Springer.

Bakker, A. B., \& Demerouti, E. (2007). The job demands-resources model: State of the art. Journal of Managerial Psychology, 22(3), 309-328. https://doi.org/10.1108/02683940710733115.

Bandura, A. (1986). Social foundations of thought and action: A social cognitive theory. Englewood Cliffs, NJ: Prentice Hall.

Bass, B. M. (1991). From transactional to transformational leadership: Learning to share the vision. Organizational Dynamics, 18(3), 19-31. https://doi.org/10.1016/0090-2616(90)90061-S.

Baumeister, R. F., \& Leary, M. R. (1995). The need to belong: Desire for interpersonal attachments as a fundamental human motivation. Psychological Bulletin, 117(3), 497-529.

Benit, N., \& Soellner, R. (2013). Scientist-practitioner gap in Deutschland: Eine empirische Studie am Beispiel psychologischer Testverfahren [Scientist-practitioner gap in Germany: An empirical study exemplified by psychological tests]. Zeitschrift Für Arbeits- und Organisationspsychologie A\&O, 57(3), 145153. https://doi.org/10.1026/0932-4089/a000111.

Blair, C. A., Helland, K., \& Walton, B. (2017). Leaders behaving badly: The relationship between narcissism and unethical leadership. Leadership \& Organization Development Journal, 38(2), 333-346. https://doi.org/10.1108/LODJ-09-2015-0209.

Blair, C. A., Hoffman, B. J., \& Helland, K. R. (2008). Narcissism in organizations: A multisource appraisal reflects different perspectives. Human Performance, 21(3), 254-276. https://doi. org/10.1080/08959280802137705.

Bradlee, P. M., \& Emmons, R. A. (1992). Locating narcissism within the interpersonal circumplex and the five-factor model. Personality and Individual Differences, 13(7), 821-830. https://doi. org/10.1016/0191-8869(92)90056-U.

Braun, S. (2017). Leader narcissism and outcomes in organizations: A review at multiple levels of analysis and implications for future research. Frontiers in Psychology, 8, 1-22. https://doi. org/10.3389/fpsyg.2017.00773.

Braun, S., Aydin, N., Frey, D., \& Peus, C. (2018). Leader narcissism predicts malicious envy and supervisor-targeted counterproductive work behavior: Evidence from field and experimental research. Journal of Business Ethics, 151, 725-741. https://doi. org/10.1007/s10551-016-3224-5.

Brislin, R. W. (1986). The wording and translation of research instruments. In W. J. Lonner \& J. W. Berry (Eds.), Field methods in cross-cultural research (pp. 137-164). Beverly Hills, CA: Sage. 
Brunell, A. B., \& Campbell, W. K. (2011). Narcissism and romantic relationships: Understanding the Paradox. In W. K. Campbell \& J. D. Miller (Eds.), The handbook of narcissism and narcissistic personality disorder: Theoretical approaches, empirical findings, and treatments (pp. 344-350). Hoboken, NJ: Wiley.

Brunell, A. B., Gentry, W. A., Campbell, W. K., Hoffman, B. J., Kuhnert, K. W., \& Demarree, K. G. (2008). Leader emergence: The case of the narcissistic leader. Personality and Social Psychology Bulletin, 34(12), 1663-1676. https://doi.org/10.1177/01461 67208324101.

Bushman, B. J., \& Baumeister, R. F. (1998). Threatened egotism, narcissism, self-esteem, and direct and displaced aggression: Does self-love or self-hate lead to violence? Journal of Personality and Social Psychology, 75(1), 219-229. https://doi.org/10.1037/ e552692012-026.

Campbell, W. K., Brunell, A. B., \& Finkel, E. J. (2006). Narcissism, interpersonal self-regulation, and romantic relationships: An agency model approach. In E. J. Finkel \& K. D. Vohs (Eds.), Self and relationships: Connecting intrapersonal and interpersonal processes (pp. 57-83). New York: Guilford Press.

Campbell, W. K., \& Campbell, S. M. (2009). On the self-regulatory dynamics created by the peculiar benefits and costs of narcissism: A contextual reinforcement model and examination of leadership. Self and Identity, 8(2-3), 214-232. https://doi.org/10.1080/15298 860802505129

Campbell, W. K., \& Foster, C. A. (2002). Narcissism and commitment in romantic relationships: An investment model analysis. Personality and Social Psychology Bulletin, 28(4), 484-495. https://doi. org/10.1177/0146167202287006.

Campbell, W. K., Hoffman, B. J., Campbell, S. M., \& Marchisio, G. (2011). Narcissism in organizational contexts. Human Resource Management Review, 21(4), 268-284. https://doi.org/10.1016/j. hrmr.2010.10.007.

Carlson, E. N. (2013). Honestly arrogant or simply misunderstood? Narcissists' awareness of their narcissism. Self and Identity, 12(3), 259-277. https://doi.org/10.1080/15298868.2012.659427.

Carlson, E. N., Vazire, S., \& Furr, R. M. (2011). Meta-insight: Do people really know how others see them? Journal of Personality and Social Psychology, 101(4), 831-846. https://doi.org/10.1037/ a0024297.

Chen, L. (2016). Linking leader personality traits to motivation to lead: A self-concept approach. Social Behavior and Personality, 44(11), 1913-1926. https://doi.org/10.2224/ sbp.2016.44.11.1913.

Chang, C.-M., Wu, C.-S., Mui, W.-C., \& Lin, Y.-H. (2018). The impact of perceived supervisor support and workplace friendship on organizational citizenship behavior in sport center. International Journal of Organizational Innovation, 10(4), 140-149.

Chatterjee, A., \& Hambrick, D. C. (2007). It's all about me: Narcissistic chief executive officers and their effects on company strategy and performance. Administrative Science Quarterly, 52(3), 351-386. https://doi.org/10.2189/asqu.52.3.351.

Chopik, W. J., \& Grimm, K. J. (2019). Longitudinal changes and historic differences in narcissism from adolescence to older adulthood. Psychology and Aging, 34(8), 1109-1123. https://doi. org/10.1037/pag0000379.

Clark, M. S., \& Mills, J. R. (2011). A theory of communal (and exchange) relationships. In P. A. M. Van Lange, A. W. Kruglanski, \& E. T. Higgins (Eds.), The handbook of theories of social psychology (pp. 232-250). Los Angeles: Sage.

Connelly, B. S., \& Ones, D. S. (2010). An other perspective on personality: Meta-analytic integration of observers' accuracy and predictive validity. Psychological Bulletin, 136(6), 1092-1122. https://doi.org/10.1037/a0021212.
Craig, R., \& Amernic, J. (2011). Detecting linguistic traces of destructive narcissism at-a-distance in a CEO's letter to shareholders. Journal of Business Ethics, 101(4), 563-575.

Cropanzano, R., Dasborough, M. T., \& Weiss, H. M. (2017). Affective events and the development of leader-member exchange. Academy of Management Review, 42(2), 233-258. https://doi. org/10.5465/amr.2014.0384.

Cropanzano, R., \& Mitchell, M. S. (2005). Social exchange theory: An interdisciplinary review. Journal of Management, 31(6), 874-900. https://doi.org/10.1177/0149206305279602.

De Hoogh, A. H. B., Den Hartog, D. N., \& Nevicka, B. (2015). Gender differences in the perceived effectiveness of narcissistic leaders. Applied Psychology, 64(3), 473-498. https://doi.org/10.1111/ apps. 12015.

Den Hartog, D. N., De Hoogh, A. H. B., \& Belschak, F. D. (2020). Toot your own horn? Leader narcissism and the effectiveness of employee self-promotion. Journal of Management, 46(2), 261-286. https://doi.org/10.1177/0149206318785240.

Dulebohn, J. H., Bommer, W. H., Liden, R. C., Brouer, R. L., \& Ferris, G. R. (2012). A meta-analysis of antecedents and consequences of leader-member exchange: Integrating the past with an eye towards the future. Journal of Management, 38(6), 1715-1759. https://doi.org/10.1177/0149206311415280.

Eisenberger, R., Cummings, J., Armeli, S., \& Lynch, P. (1997). Perceived organizational support, discretionary treatment, and job satisfaction. Journal of Applied Psychology, 82(5), 812-820. https://doi.org/10.1037/0021-9010.82.5.812.

Eisenberger, R., Stinglhamber, F., Vandenberghe, C., Sucharski, I. L., \& Rhoades, L. (2002). Perceived supervisor support: Contributions to perceived organizational support and employee retention. Journal of Applied Psychology, 87(3), 565-573. https://doi.org/10.1037//0021-9010.87.3.565.

Ellen, B. P., Kiewitz, C., Garcia, P. R. J. M., \& Hochwarter, W. A. (2017). Dealing with the full-of-self-boss: Interactive effects of supervisor narcissism and subordinate resource management ability on work outcomes. Journal of Business Ethics, 157(3), 847-864. https://doi.org/10.1007/s10551-017-3666-4.

Epitropaki, O., Sy, T., Martin, R., Tram-Quon, S., \& Topakas, A. (2013). Implicit leadership and followership theories "in the wild": Taking stock of information-processing approaches to leadership and followership in organizational settings. The Leadership Quarterly, 24(6), 858-881.

Geßler, S., Nezlek, J. B., \& Schütz, A. (2020). Training emotional intelligence: Does training in basic emotional abilities help people to improve higher emotional abilities? The Journal of Positive Psychology. https://doi.org/10.1080/17439 760.2020 .1738537$.

Geukes, K., Nestler, S., Hutteman, R., Dufner, M., Küfner, A. C. P., Egloff, B., et al. (2017). Puffed-up but shaky selves: State selfesteem level and variability in narcissists. Journal of Personality and Social Psychology, 112(5), 769-786. https://doi.org/10.1037/ pspp0000093.

Graen, G. B., \& Scandura, T. A. (1987). Toward a psychology of dyadic organizing. Research in Organizational Behavior, 9, 175-208.

Graen, G. B., \& Uhl-Bien, M. (1995). Relationship-based approach to leadership: Development of Leader-Member Exchange (LMX) Theory of Leadership over 25 Years: Applying a multi-level multi-domain perspective. Leadership Quarterly, 6(2), 219-247.

Grapsas, S., Brummelman, E., Back, M. D., \& Denissen, J. J. A. (2019). The "why" and "how" of narcissism: A process model of narcissistic status pursuit. Perspectives on Psychological Science, 15(1), 150-172. https://doi.org/10.1177/1745691619873350.

Grijalva, E., Harms, P. D., Newman, D. A., Gaddis, B. H., \& Fraley, R. C. (2015). Narcissism and leadership: A meta-analytic review of linear and nonlinear relationships. Personnel Psychology, 68(1), 1-47. https://doi.org/10.1111/peps.12072. 
Grijalva, E., \& Zhang, L. (2016). Narcissism and self-insight: A review and meta-analysis of narcissists' self-enhancement tendencies. Personality and Social Psychology Bulletin, 42(1), 3-24. https ://doi.org/10.1177/0146167215611636.

Grosz, M. P., Göllner, R., Rose, N., Spengler, M., Trautwein, U., Rauthmann, J. F., et al. (2019). The development of narcissistic admiration and machiavellianism in early adulthood. Journal of Personality and Social Psychology, 116(3), 467-482. https://doi. org/10.1037/pspp0000174.

Harris, M. A., \& Orth, U. (2019). The link between self-esteem and social relationships: A meta-analysis of longitudinal studies. Journal of Personality and Social Psychology. https://doi. org/10.1037/pspp0000265.

Heatherton, T. F., \& Polivy, J. (1991). Development and validation of a scale for measuring state self-esteem. Journal of Personality and Social Psychology, 60(6), 895-910. https://doi. org/10.1037/0022-3514.60.6.895.

Heck, R. (2015). An Introduction to Multilevel Modeling Techniques: MLM and SEM Approaches Using Mplus, Third Edition (Quantitative Methodology Series). New York, NY: Routledge.

Hepper, E. G., Hart, C. M., \& Sedikides, C. (2014). Moving narcissus: Can narcissists be empathic? Personality and Social Psychology Bulletin, 40(9), 1079-1091.

Higgs, M. (2009). The good, the bad and the ugly: Leadership and narcissism. Journal of Change Management, 9(2), 165-178. https:// doi.org/10.1080/14697010902879111.

Hobman, E. V., Restubog, S. L. D., Bordia, P., \& Tang, R. L. (2009). Abusive supervision in advising relationships: Investigating the role of social support. Applied Psychology, 58(2), 233-256. https ://doi.org/10.1111/j.1464-0597.2008.00330.x.

Hochwarter, W. A., \& Thompson, K. W. (2012). Mirror, mirror on my boss's wall: Engaged enactment's moderating role on the relationship between perceived narcissistic supervision and work outcomes. Human Relations, 65(3), 335-366. https://doi. org/10.1177/0018726711430003.

Hoffman, B. J., Strang, S. E., Kuhnert, K. W., Campbell, W. K., Kennedy, C. L., \& LoPilato, A. C. (2013). Leader narcissism and ethical context. Journal of Leadership and Organizational Studies, 20(1), 25-37. https://doi.org/10.1177/1548051812465891.

Hogan, R., \& Fico, J. (2011). Leadership. In W. K. Campbell \& J. D. Miller (Eds.), The handbook of narcissism and narcissistic personality disorder: Theoretical approaches, empirical findings, and treatments (pp. 393-402). Hoboken, NJ: Wiley.

Holt-Lunstad, J., Smith, T. B., \& Layton, J. B. (2010). Social relationships and mortality risk: A meta-analytic review. PLoS Medicine, 7(7), e1000316. https://doi.org/10.1371/journal.pmed.1000316.

Hossiep, R., Schecke, J., \& Weiß, S. (2015). Zum Einsatz von persönlichkeitsorientierten Fragebogen: Erhebung unter den 580 größten deutschen Unternehmen [On the use of personality-oriented questionnaires: Survey among the 580 largest German companies]. Psychologische Rundschau, 66(2), 127-129. https://doi. org/10.1026/0033-3042/a000235.

Hox, J. J. (2010). Multilevel analysis: Techniques and applications: Quantitative methodology series (2nd ed.). New York, NY: Routledge.

Huang, L., Krasikova, D. V., \& Harms, P. D. (2020). Avoiding or embracing social relationships? A conservation of resources perspective of leader narcissism, leader-member exchange differentiation, and follower voice. Journal of Organizational Behavior, 41, 77-92. https://doi.org/10.1002/job.2423.

Judge, T. A., \& Bono, J. E. (2001). Relations of core self-evaluations traits - self-esteem, generalized self-efficacy, locus of control, and emotional stability - with job satisfaction and job performance: A meta-analysis. Journal of Applied Psychology, 86, 80-92.
Judge, T. A., Jackson, C. L., Shaw, J. C., Scott, B. A., \& Rich, B. L. (2007). Self-efficacy and work-related performance: The integral role of individual differences. Journal of Applied Psychology, 92(1), 107-127. https://doi.org/10.1037/0021-9010.92.1.107.

Judge, T. A., LePine, J. A., \& Rich, B. L. (2006). Loving yourself abundantly: Relationship of the narcissistic personality to selfand other perceptions of workplace deviance, leadership, and task and contextual performance. Journal of Applied Psychology, 91(4), 762-776. https://doi.org/10.1037/0021-9010.91.4.762.

Kahn, J. H. (2011). Multilevel modeling: Overview and applications to research in counseling psychology. Journal of Counseling Psychology, 58(2), 257-271. https://doi.org/10.1037/a0022680.

Kahn, W. A. (1990). Psychological conditions of personal engagement and disengagement at work. Academy of Management Journal, 33(4), 692-724. https://doi.org/10.5465/256287.

Katz, D., \& Kahn, R. L. (1978). The social psychology of organizations. New York: Wiley.

Kenny, D. A., \& Cook, W. L. (1999). Partner effects in relationship research: Conceptual issues, analytic difficulties, and illustrations. Personal Relationships, 6(4), 433-448. https://doi. org/10.1111/j.1475-6811.1999.tb00202.x.

Kernis, M. H., \& Sun, C.-R. (1994). Narcissism and reactions to interpersonal feedback. Journal of Research in Personality, 28(1), 4-13.

Köppe, C., Held, M., \& Schütz, A. (2019). Improving emotion perception and emotion regulation through a web-based emotional intelligence training (WEIT) program for future leaders. International Journal of Emotional Education, 11(2), 17-32.

Kotter, J. P. (1990). A force for change: How leadership differs from management. New York: Free Press.

Krizan, Z., \& Herlache, A. D. (2018). The narcissism spectrum model: A synthetic view of narcissistic personality. Personality and Social Psychology Review, 22(1), 3-31. https://doi. org/10.1177/1088868316685018.

Krohne, H. W., Egloff, B., Kohlmann, C.-W., \& Tausch, A. (1996). Untersuchungen mit einer deutschen Version der "Positive and Negative Affect Schedule" (PANAS) [Investigations with a German version of the Positive and Negative Affect Schedule (PANAS)]. Diagnostica, 42, 139-156.

Küfner, A. C. P., Nestler, S., \& Back, M. D. (2013). The two pathways to being an (un-)popular narcissist. Journal of Personality, 81(2), 184-195. https://doi.org/10.1111/j.1467-6494.2012.00795.x.

Lange, J., Crusius, J., \& Hagemeyer, B. (2016). The evil queen's dilemma: Linking narcissistic admiration and rivalry to benign and malicious envy. European Journal of Personality, 30(2), 168-188. https://doi.org/10.1002/per.2047.

Lavner, J. A., Lamkin, J., Miller, J. D., Campbell, W. K., \& Karney, B. R. (2016). Narcissism and newlywed marriage: Partner characteristics and marital trajectories. Personality Disorders, 7(2), 169-179. https://doi.org/10.1037/per0000137.

Leary, M. R., \& Baumeister, R. F. (2000). The nature and function of self-esteem: Sociometer theory. Advances in Experimental Social Psychology, 32, 1-62.

LeBreton, J. M., Barksdale, C. D., Robin, J., \& James, L. R. (2007). Measurement issues associated with conditional reasoning tests: Indirect measurement and test faking. Journal of Applied Psychology, 92(1), 1-16. https://doi.org/10.1037/0021-9010.92.1.1.

Leckelt, M., Küfner, A. C. P., Nestler, S., \& Back, M. D. (2015). Behavioral processes underlying the decline of narcissists' popularity over time. Journal of Personality and Social Psychology, $109(5), 856-871$

Lepore, S. J. (1992). Social conflict, social support, and psychological distress: Evidence of cross-domain buffering effects. Journal of Personality and Social Psychology, 63(5), 857-867. https://doi. org/10.1037/0022-3514.63.5.857. 
Liu, H., Chiang, J. T., Fehr, R., Xu, M., \& Wang, S. (2017). How do leaders react when treated unfairly? Leader narcissism and self-interested behavior in response to unfair treatment. Journal of Applied Psychology, 102(11), 1590-1599. https://doi. org/10.1037/ap10000237.

Maccoby, M. (2000). Narcissistic leaders: The incredible pros, the inevitable cons. Harvard Business Review, 78(1), 69-77. https ://doi.org/10.4324/9781315250601-4.

Malesza, M., \& Kaczmarek, M. C. (2018). The convergent validity between self- and peer-ratings of the Dark Triad personality. Current Psychology, 11(4), 303. https://doi.org/10.1007/s1214 4-018-9906-7.

Martin, R., Epitropaki, O., Thomas, G., \& Topakas, A. (2010). A review of leader-member exchange research: Future prospects and directions. In G. P. Hodgkinson \& J. K. Ford (Eds.), International review of industrial and organizational psychology (Vol. 74, pp. 35-88). Oxford: Wiley-Blackwell.

Martin, S. R., Côté, S., \& Woodruff, T. (2016). Echoes of our upbringing: How growing up wealthy or poor relates to narcissism, leader behavior, and leader effectiveness. Academy of Management Journal, 59(6), 2157-2177. https://doi.org/10.5465/ amj.2015.0680.

Mellor, D., Stokes, M., Firth, L., Hayashi, Y., \& Cummins, R. (2008). Need for belonging, relationship satisfaction, loneliness, and life satisfaction. Personality and Individual Differences, 45(3), 213-218. https://doi.org/10.1016/j.paid.2008.03.020.

Miller, J. D., Lynam, D. R., \& Campbell, W. K. (2016). Measures of narcissism and their relations to DSM-5 pathological traits: A critical reappraisal. Assessment, 23(1), 3-9. https://doi. org/10.1177/1073191114522909.

Mota, S., Humberg, S., Krause, S., Fatfouta, R., Geukes, K., SchröderAbé, M., et al. (2019). Unmasking Narcissus: A competitive test of existing hypotheses on (agentic, antagonistic, neurotic, and communal) narcissism and (explicit and implicit) self-esteem across 18 samples. Self and Identity, 18(1), 1-21. https://doi. org/10.1080/15298868.2019.1620012.

Muthén, L. K., \& Muthén, B. O. (1998-2012). Mplus user's guide (7th ed.). Los Angeles, CA: Muthén \& Muthén.

Nevicka, B., De Hoogh, A. H. B., Den Hartog, D. N., \& Belschak, F. D. (2018a). Narcissistic leaders and their victims: Followers low on self-esteem and low on core self-evaluations suffer most. Frontiers in Psychology, 9, 1-14. https://doi.org/10.3389/fpsyg .2018.00422.

Nevicka, B., De Hoogh, A. H. B., Van Vianen, A. E. M., Beersma, B., \& McIlwain, D. (2011a). All I need is a stage to shine: Narcissist's leader emergence and performance. The Leadership Quarterly, 22, 910-925.

Nevicka, B., Ten Velden, F. S., De Hoogh, A. H. B., \& Van Vianen, A. E. M. (2011b). Reality at odds with perceptions: Narcissistic leaders and group performance. Psychological Science, 22(10), 1259-1264. https://doi.org/10.1177/0956797611417259.

Nevicka, B., Van Vianen, A. E. M., De Hoogh, A. H. B., \& Voorn, B. C. M. (2018b). Narcissistic leaders: An asset or a liability? Leader visibility, follower responses, and group-level absenteeism. Journal of Applied Psychology, 103(7), 703-723. https:// doi.org/10.1037/apl0000298.

Nezlek, J. B. (2011). Multilevel modeling for social and personality psychology. The SAGE Library of Methods in Social and Personality Psychology. London: SAGE Publications.

Ng, T. W. H., \& Sorensen, K. L. (2008). Toward a further understanding of the relationship between perceptions of support and work attitudes: A meta-analysis. Group and Organization Management, 33(3), 243-268. https://doi.org/10.1177/105960110731330 7.

Ong, C. W., Roberts, R., Arthur, C. A., Woodman, T., \& Akehurst, S. (2016). The leader ship is sinking: A temporal investigation of narcissistic leadership. Journal of Personality, 84(2), 237-247. https://doi.org/10.1111/jopy.12155.

Ostroff, C. (1992). The relationship between satisfaction, attitudes, and performance: An organizational level analysis. Journal of Applied Psychology, 77(6), 963-974. https://doi. org/10.1037/0021-9010.77.6.963.

Owens, B. P., Wallace, A. S., Walker, A. S., \& Waldman, D. A. (2015). Leader narcissism and follower outcomes: The counterbalancing effect of leader humility. Journal of Applied Psychology, 100(4), 1203-1213. https://doi.org/10.1037/a0038698.

Padilla, A., Hogan, R., \& Kaiser, R. B. (2007). The toxic triangle: Destructive leaders, susceptible followers, and conducive environments. The Leadership Quarterly, 18(3), 176-194. https://doi. org/10.1016/j.leaqua.2007.03.001.

Paul, T., \& Schyns, B. (2004). Mehrdimensionale Skala zur Erfassung des Leader-Member Exchange (LMX-MDM nach Liden \& Maslyn, 1998) [Multidimensional Scale for the Assessment of Leader-Member Exchange (LMX-MDM after Liden \& Maslyn, 1998)]. In A. Glöckner-Rist (Ed.), ZUMA-Informationssystem. Elektronisches Handbuch sozialwissenschaftlicher Erhebungsinstrumente (Version 8.00). Mannheim: Zentrum für Umfragen, Methoden und Analysen.

Paulhus, D. L. (1998). Interpersonal and intrapsychic adaptiveness of trait self-enhancement: A mixed blessing? Journal of Personality and Social Psychology, 74(5), 1197-1208. https://doi. org/10.1037//0022-3514.74.5.1197.

Paulhus, D. L. (2001). Normal narcissism: Two minimalist accounts. Psychological Inquiry, 12(4), 228-230.

Raskin, R., \& Hall, C. S. (1979). A Narcissistic Personality Inventory. Psychological Reports, 45(2), 590. https://doi. org/10.2466/pr0.1979.45.2.590.

Rich, B. L., LePine, J. A., \& Crawford, E. R. (2010). Job engagement: Antecedents and effects on job performance. Academy of Management Journal, 53(3), 617-635.

Rogoza, R., Żemojtel-Piotrowska, M., Rogoza, M., Piotrowski, J., \& Wyszyńska, P. (2016). Narcissistic admiration and rivalry in the context of personality metatraits. Personality and Individual Differences, 102, 180-185. https://doi.org/10.1016/j. paid.2016.07.003.

Rosenthal, S. A., \& Pittinsky, T. L. (2006). Narcissistic leadership. The Leadership Quarterly, 17(6), 617-633. https://doi. org/10.1016/j.leaqua.2006.10.005.

Rudolph, A., Schröder-Abé, M., \& Schütz, A. (2020). I like myself, I really do (at least right now): Development and validation of a brief and revised (German-language) version of the State SelfEsteem Scale. European Journal of Psychological Assessment, 36(1), 196-206. https://doi.org/10.1027/1015-5759/a000501.

Schuler, H., Hell, B., Trapmann, S., Schaar, H., \& Boramir, I. (2007). Die Nutzung psychologischer Verfahren der externen Personalauswahl in deutschen Unternehmen: Ein Vergleich über 20 Jahre [Use of personnel selection instruments in German organizations in the last 20 years]. Zeitschrift Für Personalpsychologie, 6(2), 60-70. https://doi.org/10.1026/1617-6391.6.2.60.

Schütz, A., Marcus, B., \& Sellin, I. (2004). Die Messung von Narzissmus als Persönlichkeitskonstrukt: Psychometrische Eigenschaften einer Lang- und einer Kurzform des Deutschen NPI (Narcissistic Personality Inventory) [Measuring narcissism as a personality construct: Psychometric properties of a long and a short version of the German NPI (Narcissistic Personality Inventory)]. Diagnostica, 50(4), 202-218. https://doi. org/10.1026/0012-1924.50.4.202.

Schwarzinger, D., \& Schuler, H. (2016). Dark Triad of Personality at Work (TOP). Göttingen: Hogrefe.

Schyns, B., Braun, S., \& Wisse, B. (2019). Dark personalities in the workplace. Oxford research encyclopedia of psychology. Oxford: Oxford University Press. 
Sguera, F., Bagozzi, R. P., Huy, Q. N., Boss, R. W., \& Boss, D. S. (2018). The more you care, the worthier I feel, the better I behave: How and when supervisor support influences (un) ethical employee behavior. Journal of Business Ethics, 153, 615-628. https://doi.org/10.1007/s10551-016-3339-8

Smith, W. K., \& Lewis, M. W. (2011). Toward a theory of paradox: A dynamic equilibrium model of organizing. The Academy of Management Review, 36, 381-403. https://doi.org/10.5465/ AMR.2011.59330958.

Snijders, T. A. B., \& Bosker, R. J. (2012). Multilevel analysis: An introduction to basic and advanced multilevel modeling (2nd ed.). Los Angeles, London, New Delhi, Singapore, Washington DC: Sage.

Spain, S. M., Harms, P., \& LeBreton, J. M. (2013). The dark side of personality at work. Journal of Organizational Behavior, 35(S1), S41-S60. https://doi.org/10.1002/job.1894.

Stajkovic, A. D., \& Luthans, F. (1998). Self-efficacy and work-related performance: A meta-analysis. Psychological Bulletin, 124(2), 240-261. https://doi.org/10.1037/0033-2909.124.2.240.

Sue-Chan, C., Au, A. K. C., \& Hackett, R. D. (2012). Trust as a mediator of the relationship between leader/member behavior and leader-member-exchange quality. Journal of World Business, 47(3), 459-468. https://doi.org/10.1016/j.jwb.2011.05.012.

Tett, R. P., \& Burnett, D. D. (2003). A personality trait-based interactionist model of job performance. Journal of Applied Psychology, 88, 500-517. https://doi.org/10.1037/0021-9010.88.3.500.

Thomas, C., Turkheimer, E., \& Oltmanns, T. F. (2003). Factorial structure of pathological personality as evaluated by peers. Journal of Abnormal Psychology, 112(1), 81-91. https://doi. org/10.1037/0021-843X.112.1.81.

Thoroughgood, C. N., Sawyer, K. B., Padilla, A., \& Lunsford, L. (2018). Destructive leadership: A critique of leader-centric perspectives and toward a more holistic definition. Journal of Business Ethics, 151, 627-649. https://doi.org/10.1007/s1055 1-016-3257-9.

Uhl-Bien, M., \& Carsten, M. K. (2007). Being ethical when the boss is not. Organizational Dynamics, 36(2), 187-201. https://doi. org/10.1016/j.orgdyn.2007.03.006.

Vazire, S., \& Mehl, M. R. (2008). Knowing me, knowing you: The accuracy and unique predictive validity of self-ratings and other-ratings of daily behavior. Journal of Personality and Social Psychology, 95(5), 1202-1216. https://doi.org/10.1037/ a0013314.

Volmer, J., Koch, I. K., \& Göritz, A. S. (2016). The bright and dark sides of leaders' dark triad traits: Effects on subordinates' career success and well-being. Personality and Individual Differences, 101, 413-418. https://doi.org/10.1016/j.paid.2016.06.046.

Waldman, D. A., Wang, D., Hannah, S. T., Owens, B. P., \& Balthazard, P. A. (2018). Psychological and neurological predictors of abusive supervision. Personnel Psychology, 71(3), 399-421. https ://doi.org/10.1111/peps.12262.

Wetzel, E., Grijalva, E., Robins, R. W., \& Roberts, B. W. (2019). You're still so vain: Changes in narcissism from young adulthood to middle age. Journal of Personality and Social Psychology. https ://doi.org/10.1037/pspp0000266.

Wetzel, E., Leckelt, M., Gerlach, T. M., \& Back, M. D. (2016). Distinguishing subgroups of narcissists with latent class analysis. European Journal of Personality, 30(4), 374-389. https://doi. org/10.1002/per.2062.

Whelpley, C. E., \& McDaniel, M. A. (2016). Self-esteem and counterproductive work behaviors: A systematic review. Journal of Managerial Psychology, 31(4), 850-863. https://doi.org/10.1108/ JMP-01-2014-0008.

Wisse, B., \& Sleebos, E. (2016). When the dark ones gain power: Perceived position power strengthens the effect of supervisor machiavellianism on abusive supervision in work teams. Personality and Individual Differences, 99, 122-126. https://doi. org/10.1016/j.paid.2016.05.019.

Wurst, S. N., Gerlach, T. M., Dufner, M., Rauthmann, J. F., Grosz, M. P., \& Küfner, A. C. P. (2017). Narcissism and romantic relationships: The differential impact of narcissistic admiration and rivalry. Journal of Personality and Social Psychology, 112(2), 280-306. https://doi.org/10.1037/pspp0000113.

Publisher's Note Springer Nature remains neutral with regard to jurisdictional claims in published maps and institutional affiliations. 